\title{
Adenocarcinoma arising from jejunal ectopic pancreas mimicking peritoneal metastasis from colon cancer: a case report and literature review
}

\author{
Yusuke Yamaoka', Tomohiro Yamaguchi ${ }^{1 *}$, Yusuke Kinugasa', Akio Shiomi ${ }^{1}$, Hiroyasu Kagawa ${ }^{1}$, Yushi Yamakawa',
} Masakatsu Numata', Shinya Sugimoto ${ }^{2}$, Kenichiro Imai ${ }^{2}$, Kinichi Hotta ${ }^{2}$ and Keiko Sasaki ${ }^{3}$

\begin{abstract}
Adenocarcinoma arising from jejunal ectopic pancreas is very rare. We report a case of a 69-year-old female with adenocarcinoma arising from jejunal ectopic pancreas after resection of advanced colon cancer. She underwent right hemicolectomy for advanced ascending colon cancer (ypT3NOMO, stage IIA) after chemotherapy. Two and half years after colectomy, her tumor markers were elevated, and computed tomography revealed a mass measuring $20 \times 20 \mathrm{~mm}$ in the small intestine, having an abnormal uptake of ${ }^{18} \mathrm{~F}$-fluorodeoxyglucose on ${ }^{18} \mathrm{~F}$-fluorodeoxyglucosepositron emission tomography $\left({ }^{18}\right.$ FDG-PET). Double-balloon enteroscopy revealed a submucosal tumor in the jejunum, and histopathology of biopsy specimens from that lesion showed ectopic pancreas without malignancy. Therefore, peritoneal metastasis from colon cancer concomitant with ectopic pancreas or adenocarcinoma arising from ectopic pancreas was considered as a differential diagnosis. She underwent laparoscopic jejunectomy. Pathological examination revealed a moderately differentiated adenocarcinoma arising from jejunal ectopic pancreas, not peritoneal metastasis from colon cancer. Even if histopathology of the biopsy specimen shows ectopic pancreas without malignancy, adenocarcinoma arising from ectopic pancreas should be considered when the tumor markers are elevated or the lesion has an abnormal uptake of ${ }^{18} \mathrm{FDG}$.
\end{abstract}

Keywords: Ectopic, Heterotopic, Aberrant, Pancreas, Adenocarcinoma, Jejunum

\section{Background}

Ectopic pancreas is defined as pancreatic tissue lacking anatomical and vascular continuity with the normally located pancreas. Ectopic pancreas is usually an asymptomatic, incidental finding at laparotomy or autopsy, and its malignant transformation is extremely rare, especially in persons with jejunal ectopic pancreas [1-3]. Therefore, adenocarcinoma arising from ectopic pancreas is difficult to diagnose before resection. The appropriate extent of lymph node dissection, the effect of chemotherapy, and the prognosis remain unclear [4]. We herein report a case of adenocarcinoma arising from jejunal ectopic pancreas with peritoneal metastasis-like

\footnotetext{
* Correspondence: t.yamaguchi@scchr.jp

'Division of Colon and Rectal Surgery, Shizuoka Cancer Center Hospital, 1007 Shimonagakubo, Nagaizumi-cho, Sunto-gun, Shizuoka 411-8777, Japan Full list of author information is available at the end of the article
}

features that occurred after resection of advanced colorectal cancer.

\section{Case presentation}

A 65-year-old Japanese female underwent ileal-colonic bypass for unresectable ascending colon cancer with invasion to the duodenum and multiple pulmonary nodules, suspected to be pulmonary metastases. She was a current smoker and had no pertinent medical history. After she received 37 cycles of chemotherapy combining folinic acid, 5-fluorouracil, irinotecan, and bevacizumab (FOLFIRI+Bev), computed tomography (CT) showed a remarkable reduction in tumor size in the ascending colon. The sizes of the patient's pulmonary nodules were not changed; hence, they were considered as benign lesions, and the primary lesion was regarded as resectable. She underwent right hemicolectomy with lymphadenectomy 
as conversion therapy. The specimen could be removed without duodenectomy. Histopathologically, the tumor was $35 \times 34 \mathrm{~mm}$, tub2, ly0, v2, ypT3, ypN0, classified as stage IIA according to the Tumor Node Metastasis Classification of the International Union Against Cancer, version 7.0 [5]. The patient maintained normal carbohydrate antigen 19-9 (CA19-9) levels $(<37 \mathrm{U} / \mathrm{mL})$ and slightly high carcinoembryonic antigen (CEA) levels at $10 \mathrm{ng} / \mathrm{mL}$ (nor$\mathrm{mal},<5.0 \mathrm{ng} / \mathrm{ml}$ ) after the colectomy. However, two and half years after the colectomy, the serum CA19-9 level and CEA level increased to $635 \mathrm{U} / \mathrm{mL}$ and $22 \mathrm{ng} / \mathrm{mL}$, respectively. CT revealed a mass measuring $20 \times 20 \mathrm{~mm}$ in the small intestine (Fig. 1a). ${ }^{18}$ F-fluorodeoxyglucosepositron emission tomography/computed tomography $\left({ }^{18} \mathrm{FDG}-\mathrm{PET} / \mathrm{CT}\right)$ revealed an abnormal uptake of ${ }^{18} \mathrm{FDG}$ in that region, with maximum standardized uptake values of 5.7 (Fig. 1b). Double-balloon enteroscopy revealed an approximately 2 -cm submucosal tumor in the jejunum at $100 \mathrm{~cm}$ from the incisor teeth. An irregular-shaped depression with a reddish color change was noted at the oral side of the lesion (Fig. 2). Histopathology of biopsy specimens from that lesion showed ectopic pancreas without malignancy. Therefore, peritoneal metastasis from colon cancer concomitant with ectopic pancreas or adenocarcinoma arising from ectopic pancreas was considered as a differential diagnosis. The patient underwent laparoscopic jejunectomy (resection of the jejunum, $20 \mathrm{~cm}$ ) with regional lymph node dissection. Peritoneal metastasis was not observed. The patient's postoperative course was uneventful. Gross examination revealed a rubbery mass measuring $28 \times 20 \mathrm{~mm}$, which had invaded the serosal surface of the jejunum. The cut surface of the tumor had a yellowish-white mass in the jejunal wall.

The findings of histopathological examination were as follows: ectopic pancreatic tissue was detected below the mucosal layer, and consisted of acini and ducts, without
Langerhans cells (Fig. 3a); moderately differentiated adenocarcinomas proliferated diffusely in an area ranging from the submucosal layer to the serosa (Fig. 3b, c); and they were also found in the epithelium of the ducts (Fig. 3d). This type of adenocarcinoma (Fig. 4a) was completely different from the previously resected colon cancer (Fig. 4b). Immunohistochemistry analysis was positive for cytokeratin 7 (CK7), mucin 1 (MUC1), and MUC5AC and negative for CK20, caudal-related homeobox gene 2 (CDX-2), and MUC6. These findings resulted in a diagnosis of adenocarcinoma arising from ectopic pancreas. A single lymph node located close to the tumor was found to be metastatic.

One month after surgery, the CA19-9 level decreased to normal, and an oral fluoropyrimidine derivative (S-1) started to be administrated as adjuvant chemotherapy, according to the protocol for treatment of resected pancreatic cancer [6]. However, the patient discontinued the chemotherapy because of adverse effects after receiving 2 cycles. Nine months after surgery, the serum CA19-9 level and CEA level increased to $273 \mathrm{U} / \mathrm{mL}$ and $28 \mathrm{ng} / \mathrm{mL}$, respectively, and CT revealed multiple nodules in the abdomen with abnormal uptakes of ${ }^{18}$ FDG. Biopsy of these lesions was recommended to the patient; however, she rejected it. Peritoneal metastasis from ectopic pancreatic adenocarcinoma was suspected rather than peritoneal metastasis from colon cancer because the serum CA19-9 level was almost normal before treatment of colon cancer was begun (Fig. 5). Therefore, gemcitabine and nab paclitaxel were administrated for recurrent pancreatic cancer. After receiving 3 cycles, she maintained stable disease.

\section{Discussion}

Ectopic pancreas is the presence of pancreatic tissue located outside the normal pancreas. It is observed in $0.5 \%$ of upper abdominal laparotomies and 0.6 to
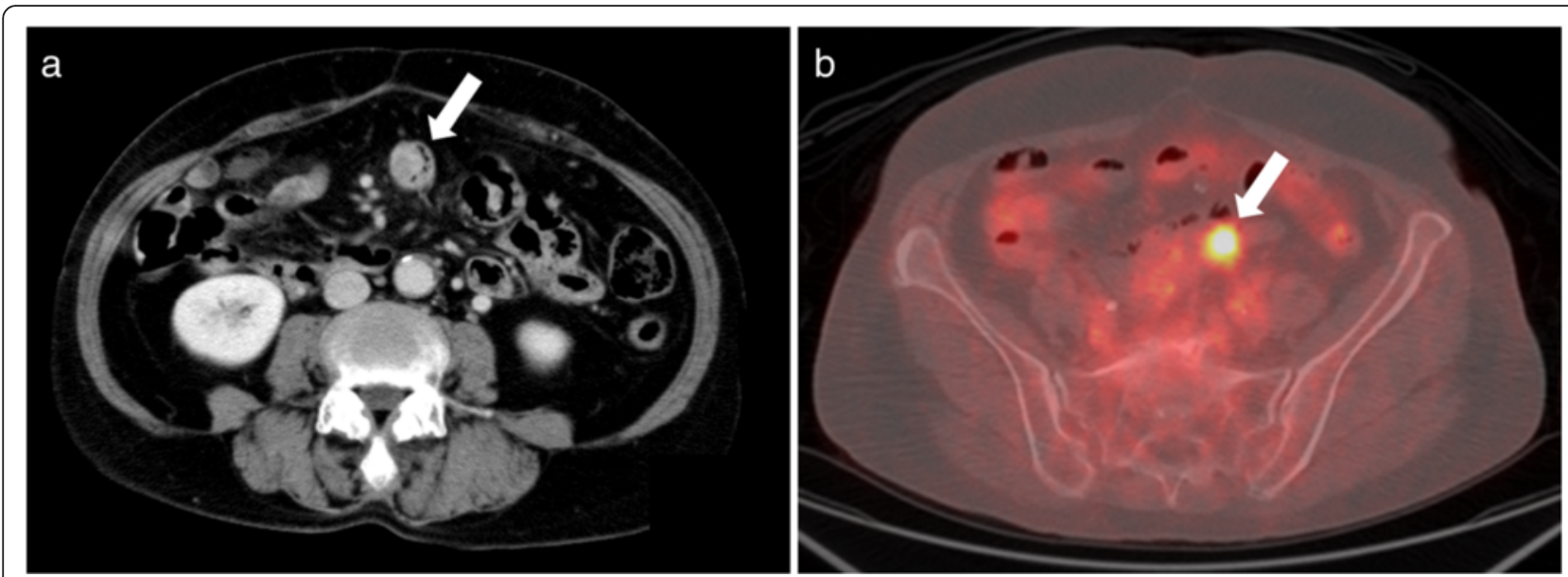

Fig. 1 Computed tomography showed a mass measuring $20 \times 20 \mathrm{~mm}$ in the small intestine (a) (arrow), and ${ }^{18} \mathrm{~F}$-fluorodeoxyglucose $\left({ }^{18} \mathrm{FDG}\right)$-positron emission tomography/computed tomography showed an abnormal uptake of ${ }^{18}$ FDG in the lesion (b) (arrow) 


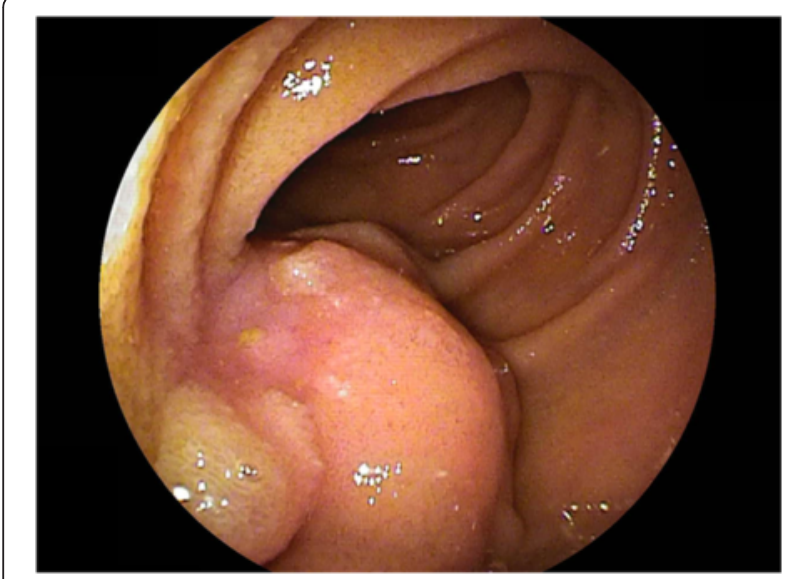

Fig. 2 Double-balloon enteroscopy showed an approximately 2-cm submucosal tumor in the jejunum at $100 \mathrm{~cm}$ from the incisor teeth

$13.7 \%$ of autopsy studies [1, 5]. It is preferentially found in the upper gastrointestinal tract (stomach $26 \%$ and duodenum $28 \%$ ), followed by the small bowel (18\%), Meckel's diverticulum (6\%), the colon, spleen, and gallbladder $[7,8]$. The Heinrich classification is widely used for pathological classification of ectopic pancreas [9]. Heinrich type I contains ducts, acini, and islets. Heinrich type II is composed of ducts and acini, lacking islets. Heinrich type III consists of ducts and smooth muscle tissue only, lacking acini and islets. Our case lacked islets, so we classified the ectopic pancreas as Heinrich type II.

The incidence of malignant transformation of ectopic pancreas has been reported to range from 0.7 to $1.8 \%$ $[7,8]$. Moreover, ectopic pancreatic carcinoma is usually located in the stomach or the duodenum; ectopic pancreas in the jejunum is extremely rare [3, 8]. Criteria have been proposed for the diagnosis of carcinoma from an ectopic pancreas as follows: (1) the tumor must be located within or near the ectopic pancreas tissue, (2) transition between pancreatic tissue and carcinoma must be observed, and (3) the non-neoplastic pancreatic tissue must comprise fully developed acini and ducts [7]. Our case satisfied these three criteria. In immunohistochemical staining, CK7, MUC1, and MUC5AC were positive, and CK20 and CDX-2 were negative, which is in good agreement with the features of ordinary pancreatic adenocarcinoma [8-10]. The histology of ectopic pancreatic adenocarcinoma was completely different from the histology of colon cancer. Thus, these pathological findings were consistent with a diagnosis of adenocarcinoma arising from jejunal ectopic pancreas, not with a diagnosis of peritoneal metastasis from colon cancer.

In our case, the tumor markers, measured for surveillance of recurrence after resection of advanced colon cancer, were elevated. CT revealed a mass with abnormal

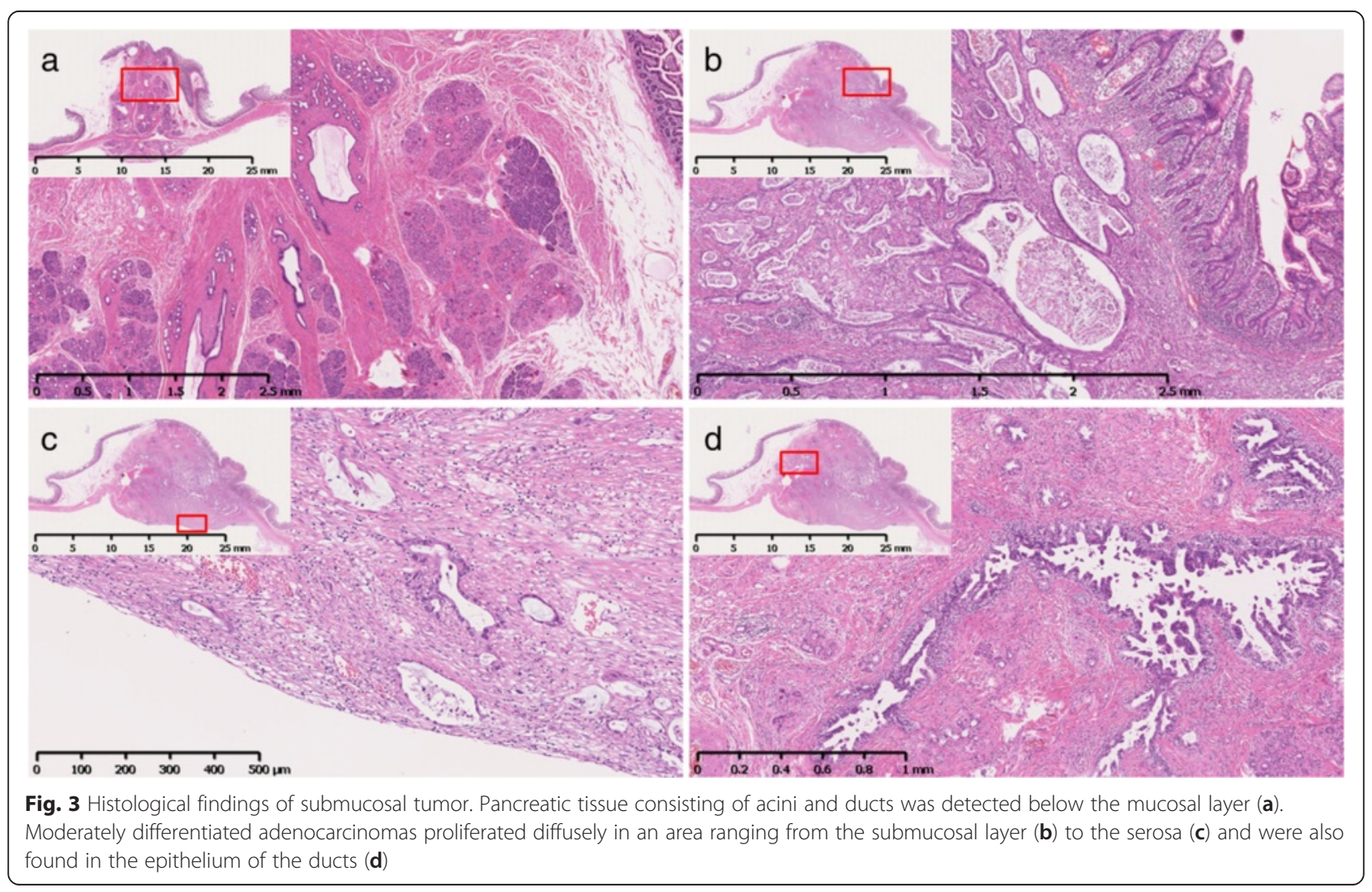




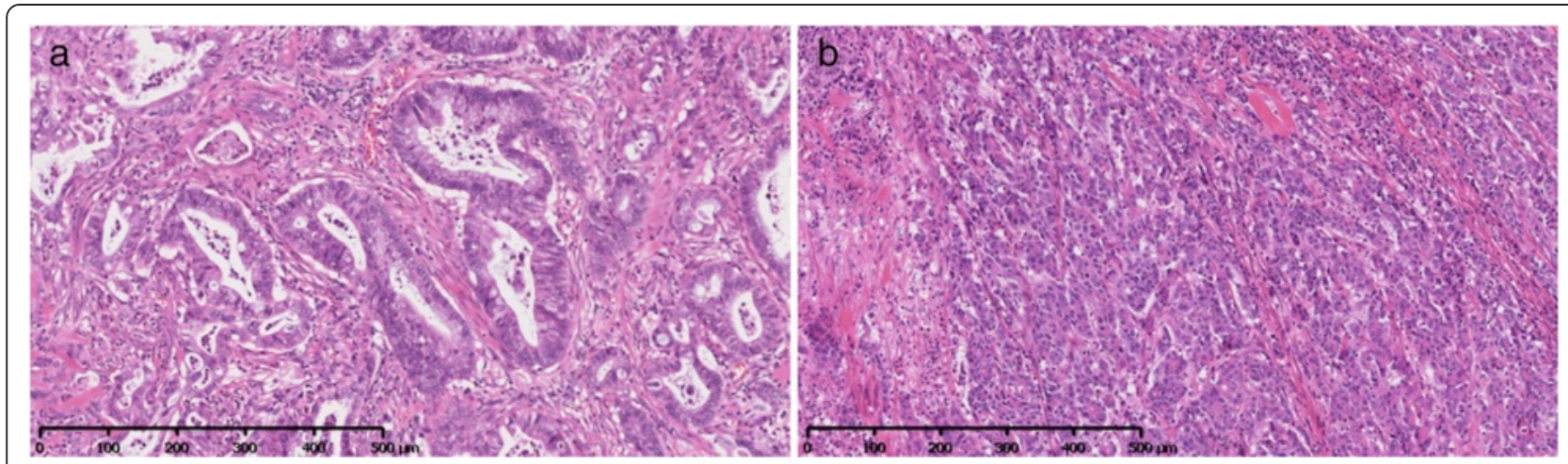

Fig. 4 Microscopic view of resected submucosal tumor in the jejunum (a) was completely different from that of previously resected colon cancer (b)

uptake of ${ }^{18}$ FDG in that region in ${ }^{18}$ FDG-PET. First, peritoneal metastasis from colon cancer or primary small intestinal cancer was suspected. However, double-balloon enteroscopy revealed a submucosal tumor in the jejunum, and histopathology of the biopsy specimens showed ectopic pancreas without malignancy. On the basis of the findings of elevated tumor marker and abnormal uptake of ${ }^{18} \mathrm{FDG}$, peritoneal metastasis from colon cancer with ectopic pancreas or adenocarcinoma arising from ectopic pancreas was considered as a differential diagnosis; therefore, resection of that lesion was required.

We performed a PubMed search of the English literature from 1966 to 2014 using the following keywords: ectopic, aberrant, heterotopic, pancreas, jejunum, small intestine, adenocarcinoma, and cancer. We also retrieved cases from the relevant reference lists. We found six

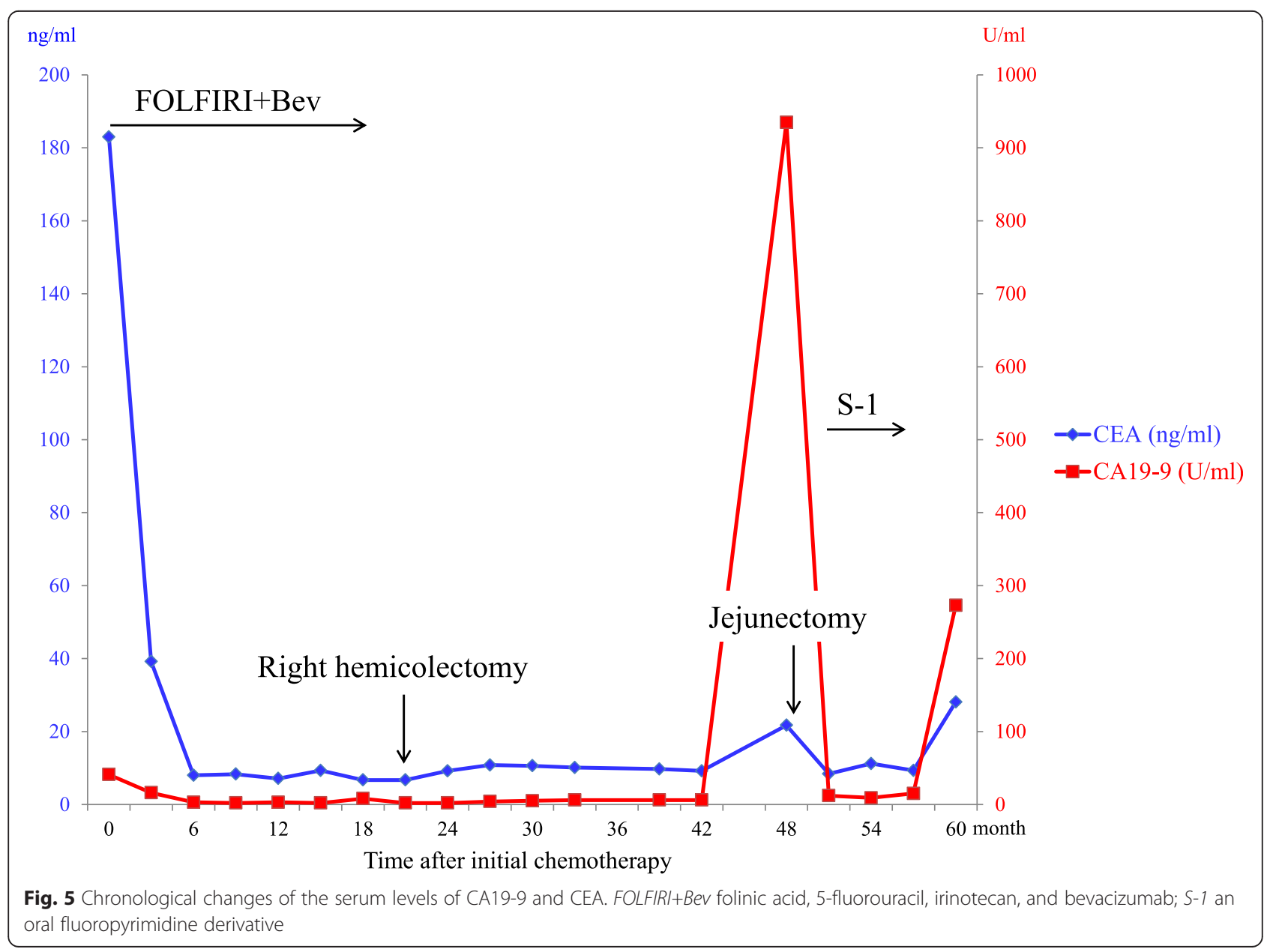


Table 1 Reported cases of adenocarcinoma arising from jejunal ectopic pancreas

\begin{tabular}{|c|c|c|c|c|c|c|c|c|c|c|c|c|}
\hline Case & Year & $\begin{array}{l}\text { Age } \\
\text { (years) }\end{array}$ & Sex & $\begin{array}{l}\text { Opportunity to } \\
\text { diagnose }\end{array}$ & CA19-9 (U/mL) & CEA (ng/mL) & Size $(\mathrm{mm})$ & $\begin{array}{l}\text { Heinrich } \\
\text { type }\end{array}$ & $\begin{array}{l}\text { Lymph node } \\
\text { metastasis }\end{array}$ & $\begin{array}{l}\text { Adjuvant } \\
\text { chemotherapy }\end{array}$ & Prognosis & Reference \\
\hline 1 & 1988 & 85 & $F$ & Bowel obstruction & ND & ND & 15 & ND & ND & ND & ND & 11 \\
\hline 2 & 1999 & 63 & M & Bowel obstruction & 6100 & 17 & $40 \times 20$ & $\|$ & ND & ND & $\begin{array}{l}\text { ND (peritoneal carcinomatosis } \\
\text { and hepatic metastasis at surgery) }\end{array}$ & 12 \\
\hline 3 & 1999 & 61 & M & Bowel obstruction & ND & ND & 15 & I & ND & ND & ND & 13 \\
\hline 4 & 2008 & 64 & $F$ & Bowel obstruction & ND & ND & 20 & ND & ND & Gemcitabine & $\begin{array}{l}\text { Death ( } 5 \text { months) (peritoneal } \\
\text { carcinomatosis) }\end{array}$ & 14 \\
\hline 5 & 2010 & 76 & $F$ & Bowel obstruction & 76 & Normal & $20 \times 15$ & III & Positive & ND & $\begin{array}{l}\text { Death ( } 5 \text { months) (hepatic } \\
\text { metastasis) }\end{array}$ & 3 \\
\hline 6 & 2012 & 74 & M & Diffuse peritonitis & 88 & Normal & 30 & $\|$ & ND & ND & ND & 15 \\
\hline $\begin{array}{l}\text { Present } \\
\text { case }\end{array}$ & 2015 & 69 & $F$ & $\begin{array}{l}\text { Elevation of tumor } \\
\text { marker }\end{array}$ & 635 & 22 & $20 \times 20$ & $\|$ & Positive & S-1 & $\begin{array}{l}\text { Not death ( } 9 \text { months) } \\
\text { (peritoneal carcinomatosis) }\end{array}$ & - \\
\hline
\end{tabular}

Normal levels of CA19-9 and CEA are below $37 \mathrm{U} / \mathrm{mL}$ and $5 \mathrm{ng} / \mathrm{mL}$, respectively

$M$ male, $F$ female, ND not described, $S-1$ an oral fluoropyrimidine derivative 
previous reports of adenocarcinoma arising from jejunal ectopic pancreas (Table 1) [3,11-15]. Six cases other than our case had abdominal symptoms. There were no cases diagnosed as adenocarcinoma arising from ectopic pancreas preoperatively. The serum CA19-9 level was predominantly elevated compared to the elevation of the serum CEA level, which was consistent with ordinary pancreatic cancer [16]. Lymph node metastasis was observed in two cases. There has been no evidence of the efficacy of chemotherapy for adenocarcinoma arising from gastrointestinal ectopic pancreas. Fukino et al. reported a case in which gemcitabine was effective for recurrent adenocarcinoma arising from duodenal ectopic pancreas [4]. The prognosis of adenocarcinoma arising from ectopic pancreas is also unclear. A few patients were reported to be alive without recurrence more than 5 years after resection of adenocarcinoma arising from ectopic gastric or duodenal pancreas, and reports have also indicated a more favorable prognosis than that for ordinary pancreatic cancer because of its earlier presentation [17-20]. However, in our literature review, four patients with adenocarcinoma arising from jejunal ectopic pancreas experienced distant metastasis, and survival time ranged from 5 to 9 months. As for adenocarcinoma arising from jejunal ectopic pancreas, the prognosis seems to be worse than that for adenocarcinoma arising from other gastrointestinal ectopic pancreases. This might result from differences in lymph node dissection. For adenocarcinoma arising from gastric or duodenal ectopic pancreas, lymph node dissection is performed according to the presence of gastric cancer or duodenal cancer. However, as for the small intestine, the efficacy and appropriate extent of lymph node dissection are unknown. More cases need to be investigated to provide some answers.

\section{Conclusions}

In summary, we report a rare case of adenocarcinoma arising from jejunal ectopic pancreas after resection of advanced colon cancer. Even if histopathology of the biopsy specimen shows ectopic pancreas without malignancy, adenocarcinoma arising from ectopic pancreas should be considered when the tumor markers are elevated or the lesion has an abnormal uptake of ${ }^{18}$ FDG.

\section{Consent}

Written informed consent was obtained from the patient for publication of this case report and any accompanying images. A copy of the written consent is available for review by the editor in chief of this journal.

\footnotetext{
Abbreviations

${ }^{18}$ FDG-PET: ${ }^{18}$ F-fluorodeoxyglucose-positron emission tomography; CA19-9: carbohydrate antigen 19-9; CDX: caudal-related homeobox gene; CEA: carcinoembryonic antigen; CK: cytokeratin; CT: computed tomography; FOLFIRI+Bev: folinic acid, 5-fluorouracil, irinotecan, and bevacizumab; MUC: mucin.
}

\section{Competing interests}

The authors declare that they have no competing interests.

\section{Authors' contributions}

$Y Y$ and $T Y$ drafted the manuscript and provided the original pictures. $Y K, A S$, $\mathrm{HK}, \mathrm{YY}, \mathrm{MN}, \mathrm{SS}, \mathrm{Kl}, \mathrm{KH}$, and $\mathrm{KS}$ collected the clinical, radiological, and pathological data and helped to draft the manuscript. YK reviewed the manuscript. All authors read and approved the final manuscript.

\section{Acknowledgements}

None.

\section{Author details}

'Division of Colon and Rectal Surgery, Shizuoka Cancer Center Hospital, 1007 Shimonagakubo, Nagaizumi-cho, Sunto-gun, Shizuoka 411-8777, Japan. ${ }^{2}$ Division of Endoscopy, Shizuoka Cancer Center Hospital, 1007 Shimonagakubo, Nagaizumi-cho, Sunto-gun, Shizuoka 411-8777, Japan. ${ }^{3}$ Division of Pathology, Shizuoka Cancer Center Hospital, 1007

Shimonagakubo, Nagaizumi-cho, Sunto-gun, Shizuoka 411-8777, Japan.

Received: 16 October 2015 Accepted: 3 November 2015

Published online: 14 November 2015

\section{References}

1. de Castro Barbosa JJ, Dockerty MB, Waugh JM. Pancreatic heterotopia; review of the literature and report of 41 authenticated surgical cases, of which 25 were clinically significant. Surg Gynecol Obstet. 1946;82:527-42.

2. Dolan RV, ReMine WH, Dockerty MB. The fate of heterotopic pancreatic tissue. A study of 212 cases. Arch Surg. 1974;109:762-5.

3. Fujiwara K, Nakahara C, Yamasaki T, Iwashita T. Adenocarcinoma of aberrant pancreas in the jejunum: report of a case. J Gastrointest Cancer. 2010;41:135-7.

4. Fukino N, Oida T, Mimatsu K, Kuboi Y, Kida K. Adenocarcinoma arising from heterotopic pancreas at the third portion of the duodenum. World J Gastroenterol. 2015;21:4082-8.

5. Sobin LH, Gospodarowicz MK, Wittekind C. International Union Against Cancer (UICC) TNM Classification of Malignant Tumors. 7th ed. Oxford, UK: Wiley-Blackwell; 2009.

6. Sudo K, Nakamura K, Yamaguchi T. S-1 in the treatment of pancreatic cancer. World J Gastroenterol. 2014;20:15110-8.

7. Guillou L, Nordback P, Gerber C, Schneider RP. Ductal adenocarcinoma arising in a heterotopic pancreas situated in a hiatal hernia. Arch Pathol Lab Med. 1994;118:568-71.

8. Goldstein NS, Bassi D. Cytokeratins 7, 17, and 20 reactivity in pancreatic and ampulla of vater adenocarcinomas. Percentage of positivity and distribution is affected by the cut-point threshold. Am J Clin Pathol. 2001;115:695-702.

9. Saad RS, Essig DL, Silverman JF, Liu Y. Diagnostic utility of CDX-2 expression in separating metastatic gastrointestinal adenocarcinoma from other metastatic adenocarcinoma in fine-needle aspiration cytology using cell blocks. Cancer. 2004;102:168-73.

10. Higashi M, Yokoyama S, Yamamoto T, Goto Y, Kitazono I, Hiraki T, et al. Mucin expression in endoscopic ultrasound-guided fine-needle aspiration specimens is a useful prognostic factor in pancreatic ductal adenocarcinoma. Pancreas. 2015:44:728-34.

11. Persson GE, Boiesen PT. Cancer of aberrant pancreas in jejunum. Case report Acta Chir Scand. 1988;154:599-601.

12. Arao J, Fukui H, Hirayama D, Miyamura S, Arao M, Hasegawa Y, et al. A case of aberrant pancreatic cancer in the jejunum. Hepatogastroenterology. 1999;46:504-7.

13. Makhlouf HR, Almeida JL, Sobin LH. Carcinoma in jejunal pancreatic heterotopia. Arch Pathol Lab Med. 1999;123:707-11.

14. Fujita K, Hirakawa K, Matsumoto T, Amano K, Yanai S, Fujioka S, et al. Small-intestinal cancer arising from heterotopic pancreas. Endoscopy. 2008;40:E240-1.

15. Song JY, Han JY, Choi SK, Kim L, Choi SJ, Park IS, et al. Adenocarcinoma with intraductal papillary mucinous neoplasm arising in jejunal heterotopic pancreas. Korean J Pathol. 2012;46:96-100.

16. Lundin J, Roberts PJ, Kuusela P, Haglund C. The prognostic value of preoperative serum levels of CA 19-9 and CEA in patients with pancreatic cancer. Br J Cancer. 1994;69:515-9. 
17. Eisenberger CF, Gocht A, Knoefel WT, Busch CB, Peiper M, Kutup A, et al. Heterotopic pancreas-clinical presentation and pathology with review of the literature. Hepatogastroenterology. 2004;51:854-8.

18. Inoue Y, Hayashi M, Arisaka Y, Higuchi K, Egashira Y, Tanigawa N.

Adenocarcinoma arising in a heterotopic pancreas (Heinrich type III): a case report. J Med Case Rep. 2010;4:39.

19. Okamoto H, Kawaoi A, Ogawara T, Fujii H. Invasive ductal carcinoma arising from an ectopic pancreas in the gastric wall: a long-term survival case. Case Rep Oncol. 2012;5:69-73.

20. Endo $S$, Saito R, Ochi D, Yamada T, Hirose M, Hiroshima Y, et al.

Effectiveness of an endoscopic biopsy procedure using EUS-FNA and EMR-C for diagnosing adenocarcinoma arising from ectopic pancreas: two case reports and a literature review. Intern Med. 2014;53:1055-62.

Submit your manuscript to a SpringerOpen ${ }^{\odot}$ journal and benefit from:

- Convenient online submission

- Rigorous peer review

- Immediate publication on acceptance

- Open access: articles freely available online

- High visibility within the field

- Retaining the copyright to your article

Submit your next manuscript at $\gg$ springeropen.com 